
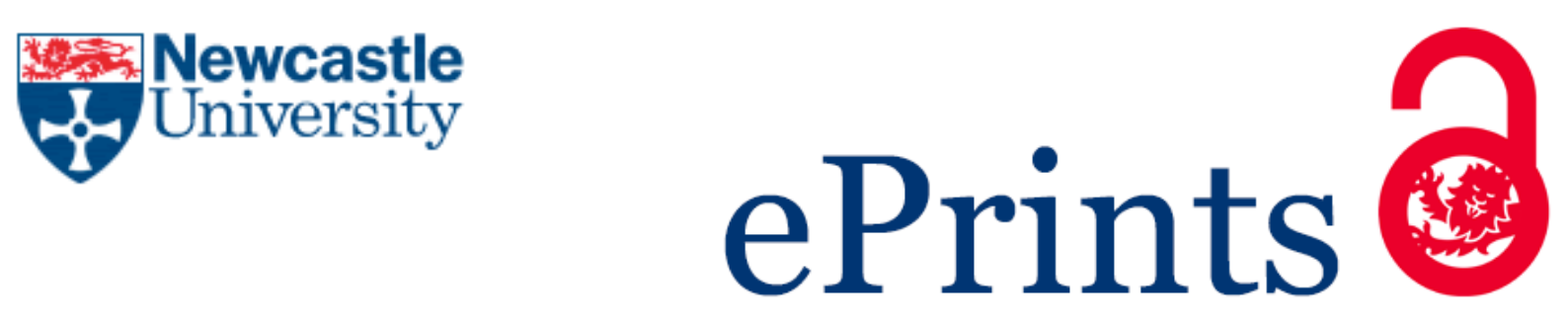

Mullaney JC, Stephens SL, Zaleski DP, Sprawling MJ, Tew DP, Walker NR, Legon AC. An Isolated Complex of Ethyne and Gold lodide Characterized by Broadband Rotational Spectroscopy and Ab initio Calculations. Journal of Physical Chemistry A 2015.

\title{
Copyright:
}

This document is the Accepted Manuscript version of a Published Work that appeared in final form in Journal of Physical Chemistry A, copyright (C2015 American Chemical Society after peer review and technical editing by the publisher. To access the final edited and published work see http://dx.doi.org/10.1021/acs.jpca.5b06593

DOI link to article:

http://dx.doi.org/10.1021/acs.jpca.5b06593

Date deposited:

$09 / 09 / 2015$

Embargo release date:

25 August 2016

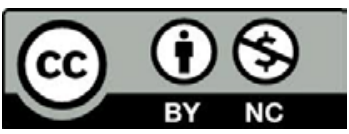

This work is licensed under a Creative Commons Attribution-NonCommercial 3.0 Unported License 
Journal of Physical Chemistry A

\section{An Isolated Complex of Ethyne and Gold Iodide Characterised by Broadband Rotational Spectroscopy and Ab initio Calculations}

John C. Mullaney, $\uparrow$ Susanna L. Stephens, $\uparrow \S$ Daniel P. Zaleski, $\uparrow$ Matthew J. Sprawling, $†$ David P. Tew,,+ Nicholas R. Walker†* and Anthony C. Legon $\dagger^{*} *$ $\uparrow$ School of Chemistry, Bedson Building, Newcastle University, Newcastle upon Tyne, Tyne and Wear, NE1 7RU, U.K.

\$School of Chemistry, University of Bristol, Bristol, BS8 1TS, U.K.

$\S$ [Current address: Chemistry Department, 360 Parker Building, University of Manitoba, Winnipeg, MB, R3T 2N2, Canada]

*Corresponding authors email: nick.walker@newcastle.ac.uk, a.c.legon@bristol.ac.uk

KEYWORDS: ethyne geometry, rotational spectroscopy, microwave spectroscopy. 


\begin{abstract}
A molecular complex of $\mathrm{C}_{2} \mathrm{H}_{2}$ and $\mathrm{AuI}$ has been generated and isolated in the gas phase through laser ablation of a gold surface in the presence of an expanding sample containing small percentages of $\mathrm{C}_{2} \mathrm{H}_{2}$ and $\mathrm{CF}_{3} \mathrm{I}$ in a buffer gas of argon. Rotational, $B_{0}$; centrifugal distortion, $\Delta_{J}$ and $\Delta_{J K}$; and nuclear quadrupole coupling constants, $\chi_{a a}(\mathrm{Au}), \chi_{b b}(\mathrm{Au})-\chi_{c c}(\mathrm{Au}), \chi_{a a}(\mathrm{I})$ and $\chi_{b b}(\mathrm{I})-\chi_{c c}(\mathrm{I})$; are measured for three isotopologues of $\mathrm{C}_{2} \mathrm{H}_{2} \cdots \mathrm{AuI}$ through broadband rotational spectroscopy. The complex is $C_{2 \mathrm{v}}$ and Tshaped with $\mathrm{C}_{2} \mathrm{H}_{2}$ coordinating to the gold atom via donation of electrons from the $\pi$-orbitals of ethyne. On formation of the complex, the $\mathrm{C} \equiv \mathrm{C}$ bond of ethyne extends by $0.032(4) \AA$ relative to $r(\mathrm{C} \equiv \mathrm{C})$ in isolated ethyne when the respective $r_{0}$ geometries are compared. The geometry of ethyne distorts such that $\angle\left({ }^{*}-\mathrm{C}-\mathrm{H}\right)$ (where $*$ indicates the midpoint of the $\mathrm{C} \equiv \mathrm{C}$ bond) is $194.7(12)^{\circ}$ in the $r_{0}$ geometry of $\mathrm{C}_{2} \mathrm{H}_{2} \cdots$ AuI. Ab initio calculations at the $\operatorname{CCSD}(\mathrm{T})(\mathrm{F} 12 *)(\mathrm{AVTZ})$ level are consistent with the experimentally-determined geometry and further allow calculation of the dissociation energy $\left(D_{\mathrm{e}}\right)$ as $136 \mathrm{~kJ} \mathrm{~mol}^{-1}$. The $\chi_{a a}(\mathrm{Au})$ and $\chi_{a a}(\mathrm{I})$ nuclear quadrupole coupling constants of AuI and also the Au-I bond length change significantly on formation of the complex consistent with the strong interaction calculated to occur between $\mathrm{C}_{2} \mathrm{H}_{2}$ and AuI.
\end{abstract}




\section{INTRODUCTION}

Although less reactive than its group 11 counterparts, gold has important uses as both a heterogeneous ${ }^{1,2}$ and homogeneous ${ }^{3,4}$ catalyst. It can exist in a variety of oxidation states from (-I) to (V) with (I) and (III) being the most common states. $\mathrm{Au}(\mathrm{I})$ is particularly prevalent ${ }^{5,6}$ in modern catalysis where it is often used in combination with a halide counterion and neutral ligands such as phosphines. Relativistic effects are highly significant in the chemistry of gold. At the focus of the present work is the interaction between the gold atom of diatomic gold iodide and ethyne. A molecular complex of $\mathrm{C}_{2} \mathrm{H}_{2} \cdots \mathrm{AuI}$ is isolated in the gaseous phase and probed by pure rotational spectroscopy to determine the molecular geometry of the complex.

It has been shown that the hydrogenation of ethyne ${ }^{7}$ can be facilitated by gold-containing catalysts. According to the Dewar-Chatt-Duncanson model $^{8}$ the geometry adopted by an alkyne or alkene when bonding to an individual metal atom results from overlap of $\pi$ orbitals on the unsaturated hydrocarbon with d orbitals on the metal atom. Complexes formed between group 11 metal ions and each of $\mathrm{C}_{2} \mathrm{H}_{2}$ and $\mathrm{C}_{2} \mathrm{H}_{4}$ have been the subject of a computational study of molecular geometries and binding strengths. ${ }^{9}$ As a consequence of relativistic effects, the bond distance separating $\mathrm{M}^{+}$and $\mathrm{C}_{2} \mathrm{H}_{2 \mathrm{n}}$ sub-units in $\mathrm{M}^{+}-\mathrm{C}_{2} \mathrm{H}_{2 \mathrm{n}}$ complexes follows a V-shaped trend on descending Group 11. The dissociation energy $\left(D_{0}\right)$ calculated for the $\mathrm{Au}^{+}-\mathrm{C}_{2} \mathrm{H}_{4}$ complex (with respect to breaking the $\mathrm{M}^{+}-\mathrm{C}_{2} \mathrm{H}_{4}$ bond) is higher than those calculated for either $\mathrm{Cu}^{+}-\mathrm{C}_{2} \mathrm{H}_{4}$ or $\mathrm{Ag}^{+}-\mathrm{C}_{2} \mathrm{H}_{4}$. Electronic photodissociation spectra have also been measured and reported for $\mathrm{Au}^{+}\left(\mathrm{C}_{2} \mathrm{H}_{4}\right) .{ }^{10}$ Pure rotational spectroscopy contributes quantitative information and benchmarks against which the results of high level calculations can be tested. The present study reports the geometry of a neutral unit and follows a number of recent computational works that have examined the geometries and binding energies of complexes where either $\mathrm{C}_{2} \mathrm{H}_{2}$ or $\mathrm{C}_{2} \mathrm{H}_{4}$ is bound to a group 11 metal atom contained within a neutral molecule. ${ }^{11-13}$

A set of empirical rules ${ }^{14,15}$ have been shown to predict correctly the geometries of a very wide range of metal-containing, hydrogen- and halogen-bonded complexes. For example, it was shown that each of $\mathrm{C}_{2} \mathrm{H}_{4} \cdots \mathrm{MCl},{ }^{16,17} \mathrm{C}_{2} \mathrm{H}_{2} \cdots \mathrm{MCl}^{16,18,19}$ (where $\mathrm{M}$ is $\mathrm{Cu}$ or $\mathrm{Ag}$ ) and $\mathrm{C}_{2} \mathrm{H}_{2} \cdots \mathrm{AgCCH}^{20}$ adopt $C_{2 \mathrm{v}}$, T- 
shaped geometries in which the $\mathrm{C}_{2} \mathrm{H}_{2}$ sub-unit forms the bar of the " $\mathrm{T}$ ". The geometries of $\mathrm{C}_{2} \mathrm{H}_{2}$ and $\mathrm{C}_{2} \mathrm{H}_{4}$ respectively distort from linearity/planarity on their attachment to $\mathrm{CuCl}$. In addition, the $\mathrm{C}-\mathrm{C}$ bond within the $\mathrm{C}_{2} \mathrm{H}_{2}$ or $\mathrm{C}_{2} \mathrm{H}_{4}$ sub-unit extends relative to its length in the free molecule. The changes are greatest in respect of $\mathrm{C}_{2} \mathrm{H}_{2} \cdots \mathrm{CuCl}$ where $\angle(\mathrm{CCH})$ expands to 192.4(7) degrees allowing the hydrogen atoms to move away from the metal atom on formation of the complex. The $\mathrm{C}=\mathrm{C}$ bond extends by $0.027(3)$ angstrom relative to its value in free $\mathrm{C}_{2} \mathrm{H}_{2}$. The corresponding changes in the geometry of $\mathrm{C}_{2} \mathrm{H}_{2}$ on formation of $\mathrm{C}_{2} \mathrm{H}_{2} \cdots \mathrm{AgCl}$ are 187.7(4) degrees and 0.017(2) angstrom. While the geometry of $\mathrm{C}_{2} \mathrm{H}_{4}$ also changes on attachment to each of $\mathrm{CuCl}$ and $\mathrm{AgCl}$, again so as to move the hydrogen atoms away from the metal atom and extend the $\mathrm{C}=\mathrm{C}$ bond, the magnitudes of the changes are smaller than those seen for $\mathrm{C}_{2} \mathrm{H}_{2}$. Evidently, the extent of the distortion of each of $\mathrm{C}_{2} \mathrm{H}_{2}$ and $\mathrm{C}_{2} \mathrm{H}_{4}$ from their free molecule geometries depends upon the identity of the attached metal atom. The greatest distortions of ethyne induced by attachment to a metal atom and observed to date were identified by Kukolich et al. ${ }^{21}$ during a study of acetylenemethyldioxorhenium in 2000 . It was reported that the $\mathrm{C} \equiv \mathrm{C}$ bond extends by $0.09 \AA$ while $\angle(\mathrm{CCH})$ expands by $26^{\circ}$ on attaching to a rhenium atom, where the quoted changes are relative to the values for the free ethyne molecule in each case. The purpose of the present work is to reveal the extent of structural changes in $\mathrm{C}_{2} \mathrm{H}_{2}$ on attaching to the gold atom of the AuI diatomic. This may be the first quantitative experimental study to measure directly the geometrical change in an unsaturated hydrocarbon following its attachment to a single gold atom within a neutral molecule.

\section{EXPERIMENTAL}

A gaseous mixture of precursors is introduced into an evacuated chamber through the circular orifice ( $0.5 \mathrm{~mm}$ in diameter) of a pulsed nozzle (Parker-Hannifin General Valve, Series 9$)$. The prepared gaseous sample contains $\sim 5 \%$ of $\mathrm{C}_{2} \mathrm{H}_{2}, \sim 2 \%$ of $\mathrm{CF}_{3} \mathrm{I}$ and the remainder is a buffer gas of argon held at a pressure of 6 bar. The mixture of gaseous precursors undergoes supersonic expansion allowing efficient collisional cooling of molecular rotational energies and the formation of weakly-bound species 
such as $\mathrm{C}_{2} \mathrm{H}_{2} \ldots \mathrm{ICF}_{3}$ within the supersonic jet. The generation of gas phase complexes of $\mathrm{C}_{2} \mathrm{H}_{2} \cdots A$ Au is achieved through vaporization of the surface of a gold metal target (gold foil attached to a brass rod) by a focused pulse of $532 \mathrm{~nm}$ radiation from a Nd:YAG laser (Continuum Minilite) in the presence of the expanding sample. The rod target is continually rotated and translated to expose fresh surface material to each laser pulse. As described within earlier publications, ${ }^{22,23}$ the plasma induced by the focused laser pulse contains a mixture of species which may undergo fragmentation, react and/or re-combine with each other. The time intervals between the laser, solenoid valve and microwave pulses are optimised to maximize the intensities of transitions of the target complex in measured spectra. With respect to the particular case of $\mathrm{C}_{2} \mathrm{H}_{2} \ldots$ AuI, it will be shown that the bond between $\mathrm{C}_{2} \mathrm{H}_{2}$ and $\mathrm{Au}$ is considerably stronger than a typical van der Waals interaction.

Studies of the most abundant isotopologue of ethyne were facilitated by a commerciallysourced cylinder of ethyne which also contains a significant sub-fraction of acetone. It is standard practice for the latter to be used as a stabilizing solvent for the former in mitigation of hazards associated with high-pressure storage of ethyne. Isotopically-enriched samples of ${ }^{13} \mathrm{C}_{2} \mathrm{D}_{2}$ and ${ }^{12} \mathrm{C}_{2} \mathrm{D}_{2}$ were employed when measuring the spectra of isotopologues containing ${ }^{13} \mathrm{C}$ and/or D atoms. Broadband rotational spectra were measured using a CP-FTMW spectrometer ${ }^{24}$ that probes all transitions between 7.5 and $18 \mathrm{GHz}$ simultaneously. Detailed descriptions of both the microwave spectrometer ${ }^{22,25-27}$ and laser ablation source ${ }^{23,28}$ used during this work have been given elsewhere. Following supersonic expansion of the prepared sample, a pulse of microwave radiation induces a macroscopic rotational polarization on resonance with a molecular rotational transition. The subsequent molecular emission, detected as the free induction decay (FID) of the polarization, is Fourier transformed to obtain the frequency domain spectrum. The experiment is repeated and averaged in the time domain to improve $\mathrm{S} / \mathrm{N}$. Propagation of the molecular beam is perpendicular to the orientation of the detecting horn such that each transition is observed as a single peak with full-width at half-maximum (fwhm) $\cong 150 \mathrm{kHz}$ after application of a Kaiser-Bessel digital filter. All frequency signals are locked to an external reference source accurate to 1 part per $10^{11}$. 


\section{Ab Initio Calculations}

Geometry optimizations were performed using $\operatorname{CCSD}(\mathrm{T})(\mathrm{F} 12 *)$, a coupled-cluster method with single and double excitations, explicit correlation, and a perturbative treatment of triple excitations $^{29,30,31}$. An AVTZ basis set combination was used, by which we mean that aug-cc-pVTZ basis sets were used for the $\mathrm{C}$ and $\mathrm{H}$ atoms ${ }^{32}$ and cc-pVTZ-PP basis sets were used for Au and $\mathrm{I}$, in combination with the ECP-28-MDF and ECP-60-MDF effective core potentials on I and Au, respectively, to account for scalar relativistic effects ${ }^{33,34,35}$. The frozen-core approximation was used throughout and all calculations were performed using the MOLPRO package ${ }^{36}$. Dissociation energies at the $\operatorname{CCSD}(\mathrm{T})(\mathrm{F} 12 *) / \mathrm{AVTZ}$ level were computed using the counterpoise correction method where, for numerical stability, the CABS singles correction was not included in the correction term.

\section{RESULTS}

\section{Initial Observations}

The broadband spectrum probed as described in Section 2 is displayed in Figure 1. Intense signals are observed for $\mathrm{CF}_{3} \mathrm{I}$ and $\mathrm{AuI}$, which have each been previously characterised. A molecular complex formed between $\mathrm{CF}_{3} \mathrm{I}$ and $\mathrm{C}_{2} \mathrm{H}_{2}$ is observed but yields transitions of somewhat lower intensities than those of $\mathrm{CF}_{3} \mathrm{I}$ and AuI. It has previously been shown ${ }^{16,19}$ that the geometries of $\mathrm{C}_{2} \mathrm{H}_{2} \cdots \mathrm{CuCl}$ and $\mathrm{C}_{2} \mathrm{H}_{2} \cdots \mathrm{AgCl}$ are each $C_{2 \mathrm{v}}$ and T-shaped with the $\mathrm{C}_{2} \mathrm{H}_{2}$ sub-unit forming the bar of the "T". These previous studies justify the initial assumptions that a complex of $\mathrm{C}_{2} \mathrm{H}_{2}$ and AuI will adopt the same basic geometry as each of $\mathrm{C}_{2} \mathrm{H}_{2} \cdots \mathrm{CuCl}$ and $\mathrm{C}_{2} \mathrm{H}_{2} \cdots \mathrm{AgCl}$ and yield a spectrum that is typical of a nearprolate asymmetric rotor. Consistent with these expectations, groups of transitions are observed in the spectrum at intervals of $\sim 1400 \mathrm{MHz}$. Each group is itself observed to comprise of three distinct bands of transitions and is tentatively assigned to a different $J^{\prime} \rightarrow J^{\prime \prime}$ transition implying a rotational constant of $\sim 700 \mathrm{MHz}$ for the molecular carrier.

The frequency intervals separating distinct bands within each $J^{\prime} \rightarrow J^{\prime \prime}$ transition are observed to increase with $J$ in a pattern consistent with assignment of the central band in each $J^{\prime} \rightarrow J^{\prime \prime}$ transition to 
components having $K_{-1}=0$ while components within the other two bands are assigned with $K_{-1}=1$. This pattern is consistent with the expected distribution of $a$-type transitions in the spectrum of a nearprolate asymmetric rotor in the described, T-shaped, $C_{2 \mathrm{v}}$ geometry. As described in previous works, ${ }^{16}$ where two equivalent nuclei are exchanged by a $C_{2}$ rotation, collisional propensity rules inhibit relaxation from $K_{-1}=1$ into $K_{-1}=0$ states of a complex. Relative intensities of the observed $K_{-1}=1$ and $K_{-1}=0$ transitions reflect the nuclear spin statistical weightings expected of a molecule containing hydrogen atoms exchanged by a $C_{2}$ rotation. The extensive and intricate splittings within each band are a consequence of hyperfine structure arising from the presence of Au $(I=3 / 2)$ and I $(I=5 / 2)$ nuclei

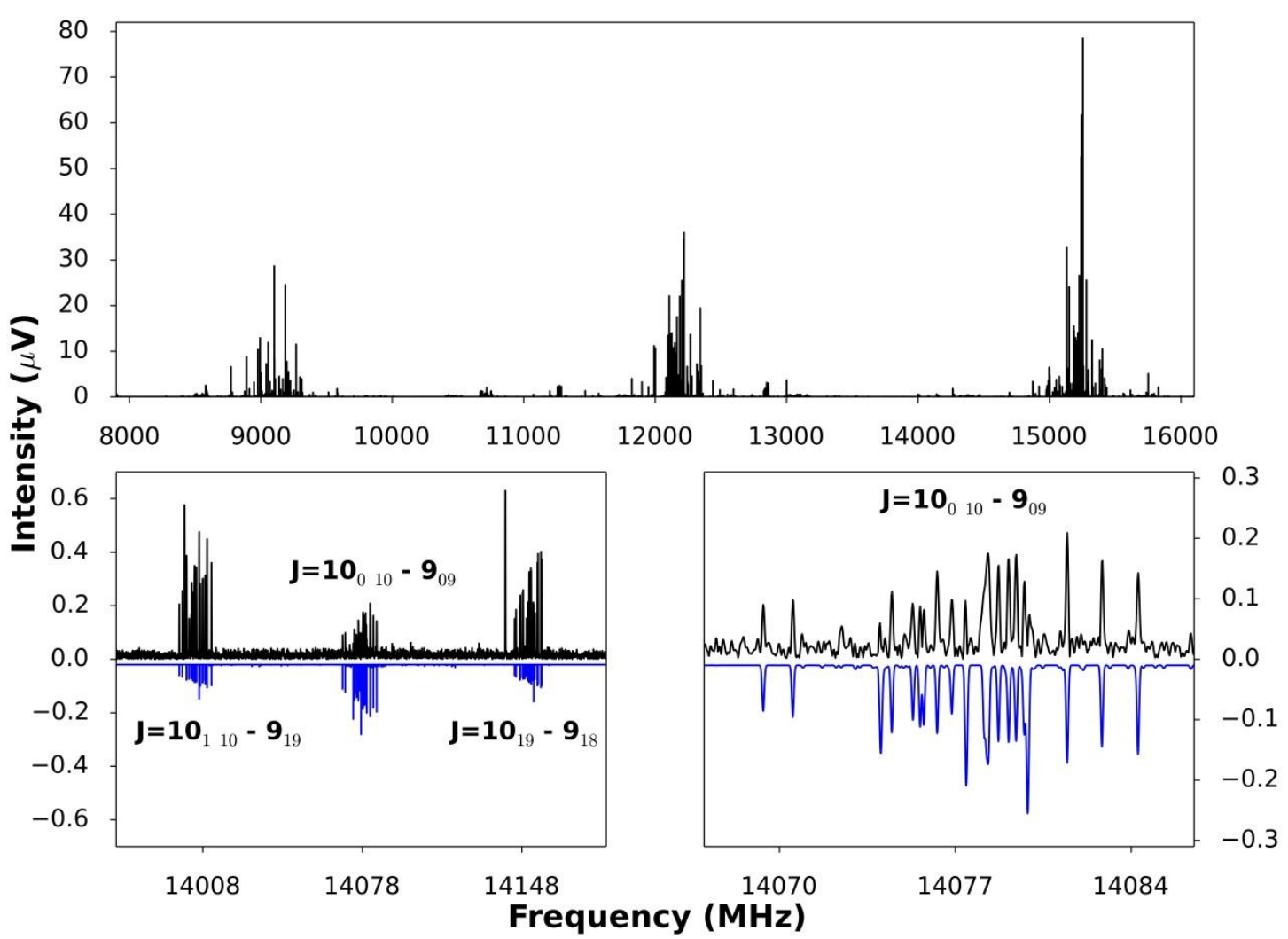

Figure 1. The upper panel shows the rotational spectrum observed (780 k FIDs) with the conditions described in the experimental text. Transitions assigned to other species such as AuI and $\mathrm{CF}_{3} \mathrm{I}$ are present while those assigned to $\mathrm{C}_{2} \mathrm{H}_{2} \cdots$ AuI are significantly less intense and not apparent in the survey spectrum. Expansions of the horizontal and vertical scales (in the bottom panels) reveals features assigned to $\mathrm{C}_{2} \mathrm{H}_{2} \cdots$ AuI with the strongest transitions having $\mathrm{S} / \mathrm{N} \sim 15: 1$. The bottom left panel shows the $J^{\prime} \rightarrow J^{\prime \prime}=10 \rightarrow 9$ transition for the $\mathrm{C}_{2} \mathrm{H}_{2} \cdots$ AuI species, with the measured spectrum in black and the simulation inverted and in blue. The intensities of transitions in the experimental spectrum result from the nuclear spin statistical weightings associated with exchange of equivalent protons by a $C_{2}$ rotation. Nuclear spin statistical weight effects are not included in the simulated spectrum. The bottom right panel shows an expansion of the $K_{-1}=0$ of $J^{\prime} \rightarrow J^{\prime \prime}=10 \rightarrow 9$. Hyperfine splitting arising from nuclear quadrupole coupling of each of Au and I is present and shown in the bottom panels. 
within the complex and are further confirmation that the carrier of the observed spectrum is a complex of $\mathrm{C}_{2} \mathrm{H}_{2}$ and $\mathrm{AuI}$ in the described $C_{2 \mathrm{v}}$, T-shaped geometry.

\section{Spectral Assignment and Spectroscopic Constants}

Measured transitions were assigned with quantum numbers in order to determine spectroscopic parameters through fitting to measured transition frequencies. Western's PGOPHER program ${ }^{37}$ was used to perform all quantum number assignments and fitting. The model Hamiltonian used to describe $\mathrm{C}_{2} \mathrm{H}_{2} \cdots$ AuI was constructed as follows;

$$
H=H_{\mathrm{R}}-\frac{1}{6} \mathbf{Q}(\mathrm{Au}): \nabla \mathbf{E}(\mathrm{Au})-\frac{1}{6} \mathbf{Q}(\mathrm{I}): \nabla \mathbf{E}(\mathrm{I})+\boldsymbol{I}_{\mathrm{Au}} \cdot \mathbf{C}_{\mathrm{Au}} \cdot \boldsymbol{J}
$$

The rotational Hamiltonian of a semi-rigid asymmetric top is denoted by $H_{\mathrm{R}}$ which includes terms in the rotational constants, $A_{0}, B_{0}$ and $C_{0}$, that respectively describe rotation of the complex about the $a, b$ and $c$ inertial axes of the complex. While a complex in the described $C_{2 \mathrm{v}}$ geometry does not have an electric dipole moment on either the $b$ - or $c$-inertial axes, the observation of $J_{0 K_{-1}^{\prime}} \rightarrow$ $(J+1)_{0 K_{-1}^{\prime \prime}}$ and $J_{1 K_{-1}^{\prime}} \rightarrow(J+1)_{1 K_{-1}^{\prime \prime}}$ transitions allows the determination of all three rotational constants, with $B_{0}$ and $C_{0}$ fitted to somewhat higher precision than $A_{0}$. The centrifugal distortion constants, $\Delta_{J}$ and $\Delta_{J K}$, are included in $H_{R}$ and fitted for all measured isotopologues of $\mathrm{C}_{2} \mathrm{H}_{2} \cdots$ AuI. The second and third terms of Eq. (1) describe the nuclear quadrupole coupling interactions between the nuclear electric quadrupole moments of the respective gold and iodine nuclei and the electric field gradients at each of these nuclei. The projections of the nuclear quadrupole coupling tensors of Au and I onto the $a$-axis, respectively denoted by $\chi_{a a}(\mathrm{Au})$ and $\chi_{a a}(\mathrm{I})$, are fitted in addition to $\chi_{b b}(\mathrm{Au})-\chi_{c c}(\mathrm{Au})$ and $\chi_{b b}(\mathrm{I})-\chi_{c c}(\mathrm{I})$.

\section{Molecular Geometry}


The observations reported above strongly imply a T-shaped, $C_{2 \mathrm{v}}$ geometry for each of $\mathrm{C}_{2} \mathrm{H}_{2} \cdots \mathrm{AuI}$ and $\mathrm{C}_{2} \mathrm{H}_{4} \cdots$ AuI. It is possible to examine this proposal more quantitatively through analysis of the fitted rotational constants. An important test of planarity involves calculation of the inertia defect, $\Delta_{0}$

$$
\Delta_{0}=I_{c}^{0}-I_{a}^{0}-I_{b}^{0}
$$

where $I_{a}^{0}, I_{b}^{0}$ and $I_{c}^{0}$ are the moments of inertia determined from the experimentally-measured $A_{0}, B_{0}$ and $C_{0}$ rotational constants. The evaluated $\Delta_{0}$ are $0.23(2), 0.37(2)$ and $0.31(1) \mathrm{u} \AA^{2}$ for ${ }^{12} \mathrm{C}_{2} \mathrm{H}_{2} \cdots$ AuI, ${ }^{12} \mathrm{C}_{2} \mathrm{D}_{2} \cdots$ AuI and ${ }^{13} \mathrm{C}_{2} \mathrm{D}_{2} \cdots$ AuI respectively. These are very similar to the inertia defects established for various isotopologues ${ }^{16}$ of $\mathrm{C}_{2} \mathrm{H}_{2} \cdots \mathrm{CuCl}$ and are slightly smaller than those determined for $\mathrm{C}_{2} \mathrm{H}_{2} \cdots \mathrm{AgCl} \cdot{ }^{19}$ These small positive results are consistent with planar geometries for these complexes. It has been noted previously ${ }^{16}$ that there is an inverse correlation between the stiffness of the intermolecular bond and the evaluated inertia defect such that $\Delta_{0}$ decreases along the series; $\mathrm{C}_{2} \mathrm{H}_{2} \cdots \mathrm{HCl}$, $\mathrm{C}_{2} \mathrm{H}_{2} \cdots \mathrm{ClF}, \mathrm{C}_{2} \mathrm{H}_{2} \cdots \mathrm{AgCCH}, \mathrm{C}_{2} \mathrm{H}_{2} \cdots \mathrm{AgCl}, \mathrm{C}_{2} \mathrm{H}_{2} \cdots \mathrm{CuCl}$. The results for $\mathrm{C}_{2} \mathrm{H}_{2} \cdots$ AuI are consistent with this trend given that the dissociation energy calculated for the complex is similar to that calculated for $\mathrm{C}_{2} \mathrm{H}_{2} \cdots \mathrm{CuCl}$ (discussed below). The inertia defects calculated for the various isotopologues of $\mathrm{C}_{2} \mathrm{H}_{2} \cdots$ AuI are displayed alongside the values of the planar moments, $P_{a}, P_{b}$ and $P_{\mathrm{c}}$, in Table 1.

Rotational constants, $A_{0}, B_{0}$ and $C_{0}$ are available for three isotopologues of $\mathrm{C}_{2} \mathrm{H}_{2} \cdots$ AuI allowing further information about the molecular geometry to be obtained through fitting of structural parameters to the experimentally-determined moments of inertia using Kisiel's STRFIT ${ }^{38}$. It is convenient to define various structural parameters with respect to the midpoint of the $\mathrm{C} \equiv \mathrm{C}$ bond, represented by an asterisk in the geometry of the complex illustrated in Figure 2. Only one isotope of each of gold and iodine is naturally-abundant reducing the confidence and precision with which the $r\left({ }^{*}-\mathrm{Au}\right)$ and $r(\mathrm{Au}-\mathrm{I})$ distances can be determined from the experimental data. The results displayed in Table 2 are obtained by fitting $r(*-\mathrm{Au}), r(\mathrm{Au}-\mathrm{I}), r(\mathrm{C} \equiv \mathrm{C})$ and $\angle\left(^{*}-\mathrm{C}-\mathrm{H}\right)$ while holding $r(\mathrm{C}-\mathrm{H})$ fixed at the value of the parameter calculated at the $\operatorname{CCSD}(\mathrm{T})\left(\mathrm{F} 12^{*}\right) / \mathrm{AVTZ}$ level after correcting for the difference between the 
experimentally measured $r_{0}$ and $r_{\mathrm{e}}$ values of $r(\mathrm{C}-\mathrm{H})$ in $\mathrm{C}_{2} \mathrm{H}_{2}$. Alternative procedures that (i) fix $r\left({ }^{*}-\mathrm{Au}\right)$ at the $a b$ initio result yields values of $r(\mathrm{Au}-\mathrm{I})=2.5008(5) \AA ⿻ \quad r(\mathrm{C} \equiv \mathrm{C})=1.234(3) \AA$, $\angle\left({ }^{*}-\mathrm{C}-\mathrm{H}\right)=193.3(6)^{\circ}$ or (ii) fix $r(\mathrm{Au}-\mathrm{I})$ at the ab initio result yields $r\left({ }^{*}-\mathrm{Au}\right)=2.005(3) \AA, r(\mathrm{C} \equiv \mathrm{C})=$ $1.248(6) \AA$ and $\left.\angle{ }^{*}-\mathrm{C}-\mathrm{H}\right)=198.0(12)^{\circ}$. Evidently, the results are somewhat sensitive to the parameter set chosen, but consistently yield an extended $\mathrm{C} \equiv \mathrm{C}$ bond length and increased $\angle\left({ }^{*}-\mathrm{C}-\mathrm{H}\right)$ compared with the geometry of free $\mathrm{C}_{2} \mathrm{H}_{2}$. The results obtained while fitting all of $r(*-\mathrm{Au}), r(\mathrm{Au}-\mathrm{I}), r(\mathrm{C} \equiv \mathrm{C})$ and $\angle(*-\mathrm{C}-\mathrm{H})$ in the $r_{0}$ geometry are closest to $\mathrm{CCSD}(\mathrm{T})\left(\mathrm{F} 12^{*}\right) / \mathrm{AVTZ}$ calculated results which are displayed alongside the $r_{0}$ and $r_{\mathrm{s}}$ results in Table 2 .

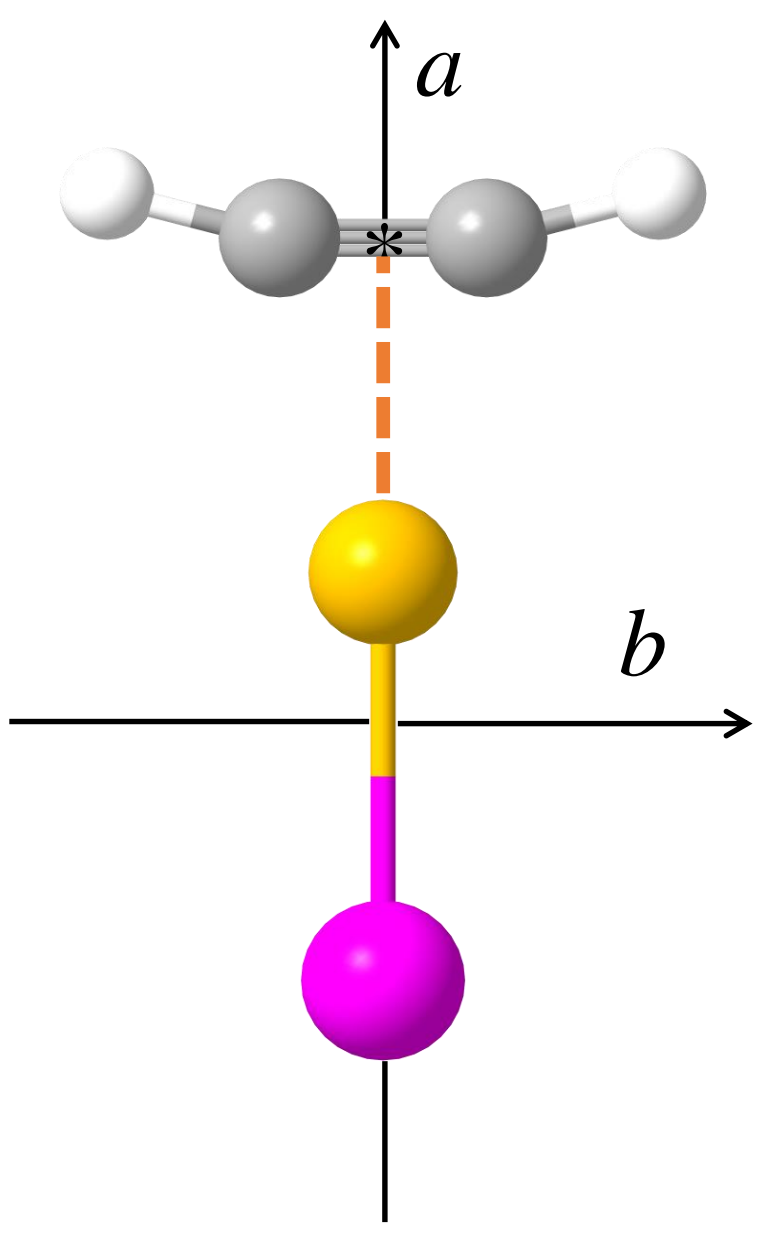

Figure 2. The geometry of $\mathrm{C}_{2} \mathrm{H}_{2} \cdots$ AuI showing the orientation of the principal inertial axes $a$ and $b$. All of the atoms lie in the $a b$ plane and $a$ is a $\mathrm{C}_{2}$ axis of rotation. The * indicates the midpoint of the $\mathrm{C} \equiv \mathrm{C}$ bond. Bond lengths and angles are to scale.

Changes in the moments of inertia on isotopic substitution can also be used to calculate coordinates for each atom and thus generate an $r_{\mathrm{s}}$ substitution geometry. Unfortunately, only one isotope of each of gold and iodine is naturally abundant so this analysis of $r_{\mathrm{s}}$ coordinates will consider only the locations of $\mathrm{C}$ and $\mathrm{H}$ atoms within the $\mathrm{C}_{2} \mathrm{H}_{2}$ sub-unit. For a $\mathrm{T}$-shaped complex where a double 
substitution is performed on atoms exchanged by a $C_{2}$ rotation, the $b$-coordinate of the substituted atom is given by ${ }^{39}$

$$
\left|b_{\mathrm{X}}\right|=\left\{\frac{\Delta I_{a}}{2 \Delta m}\right\}^{\frac{1}{2}}
$$

where $\Delta I_{a}$ is the change in the moment of inertia, $I_{a}$, on isotopic substitution of atom X and $\Delta m$ is the associated mass change on substitution. The ${ }^{12} \mathrm{C}_{2} \mathrm{D}_{2} \cdots \mathrm{AuI}$ isotopologue is selected as the parent allowing the $b$-coordinate for $\mathrm{C}$ to be determined from $\Delta I_{a}$ on substitution of ${ }^{12} \mathrm{C}$ for ${ }^{13} \mathrm{C}$ and the $b$ coordinate for $\mathrm{H}$ to be determined from $\Delta I_{a}$ on substitution of $\mathrm{H}$ for $\mathrm{D}$. The $a$ coordinate shared by the $\mathrm{C}$ atoms is calculated using

$$
\left|a_{\mathrm{X}}\right|=\left\{\frac{\Delta I_{b}}{\mu_{\mathrm{D}}}\right\}^{\frac{1}{2}}
$$

where $\mu_{\mathrm{D}}=(2 \Delta m M) /(M+2 \Delta m)$ is the reduced mass for the double substitution in the parent isotopologue of mass $M$ leading to mass change $2 \Delta m$. The values of $r(\mathrm{C} \equiv \mathrm{C})$ and $\angle\left({ }^{*}-\mathrm{C}-\mathrm{H}\right)$ implied by the $r_{s}$ results are provided in Table 2 alongside the coordinates themselves. It is apparent that the calculated substitution $\left(r_{s}\right)$ coordinates are less consistent with the ab initio results than those in the $r_{0}$ geometry, particularly in respect of $b_{\mathrm{C}}$ and $b_{\mathrm{H}}$. The $b_{\mathrm{C}}$ and $b_{\mathrm{H}}$ substitution coordinates are calculated from selected $I_{a}$ values only whereas $I_{b}$ and $I_{c}$ for each isotopologue provide additional input parameters in the fitted $r_{0}$ geometry. However, $\left.\angle{ }^{*}-\mathrm{C}-\mathrm{H}\right)$ is somewhat insensitive to the results for $b_{\mathrm{C}}$ and $b_{\mathrm{H}}$. The $\operatorname{CCSD}(\mathrm{T})(\mathrm{F} 12 *)(\mathrm{AVTZ})$ values of these parameters are $b_{\mathrm{C}}= \pm 0.617 \AA$ and $b_{\mathrm{H}}= \pm 1.655 \AA$ and using these results alongside the $r_{\mathrm{s}}$ coordinates of $a_{\mathrm{H}}$ and $a_{\mathrm{C}}$ would yield $\angle\left({ }^{*}-\mathrm{C}-\mathrm{H}\right)=194.6(7)^{\circ}$.

It is possible to assess the level of agreement that should be expected between ab initio calculations of $r_{\mathrm{e}}$ geometries at the stated level and experimentally-determined $r_{0}$ parameters through calculations performed on isolated $\mathrm{AuI}$ and $\mathrm{C}_{2} \mathrm{H}_{2}$, for which highly-accurate experimental geometries are available (Table 3). The experimentally-determined and $\operatorname{CCSD}(\mathrm{T})\left(\mathrm{F} 12^{*}\right) / \mathrm{AVTZ}$ values of $r(\mathrm{C} \equiv \mathrm{C})$ in isolated ${ }^{40} \mathrm{C}_{2} \mathrm{H}_{2}$ are within $0.003 \AA$ of each other in the $r_{\mathrm{e}}$ geometry. There is a similar level of 
agreement between theory and experiment with respect to the $r(\mathrm{C}-\mathrm{H})$ parameter. As expected, bond distances in the $r_{0}$ geometry are slightly longer (by $0.001 \AA$ ) than those in the $r_{\text {e }}$ geometry as a consequence of vibrational motion in the zero-point state. Calculation of $r(\mathrm{Au}-\mathrm{I})$ of free $\mathrm{AuI}$ at the stated level of theory yields a result that is $0.02 \AA$ longer than the experimentally-determined $r_{\mathrm{e}}$ parameter. Extrapolating the calculation to the basis set limit yields only a very small $(0.001 \AA)$ reduction in the calculated bond length and a full treatment of triple and quadruple excitations also has only a very small effect. However, contributions from core-valence correlation are much greater and their inclusion reduces the value of the calculated parameter by $0.014 \AA$. The remaining difference between the calculated and experimentally-determined $r_{\mathrm{e}}$ values for $r(\mathrm{Au}-\mathrm{I})$ arises because of the lowlevel treatment of relativity used.

Examining the results for the $\mathrm{C}_{2} \mathrm{H}_{2} \cdots$ AuI complex, it must first be noted that the experiment yields an $r_{0}$ geometry while the $\operatorname{CCSD}(\mathrm{T})(\mathrm{F} 12 *) / \mathrm{AVTZ}$ calculation is for the $r_{\mathrm{e}}$ geometry. The implication of vibrational motion in the zero-point state, as stated above, is that the value of the $r(\mathrm{Au}-\mathrm{I})$ parameter in the $r_{0}$ geometry can be expected to be $\sim 0.002 \AA$ longer than that in the $r_{\mathrm{e}}$ geometry. Noting the discussion above, the $\sim 0.02 \AA$ difference between the $\operatorname{CCSD}(\mathrm{T})(\mathrm{F} 12 *) / \operatorname{AVTZ}\left(r_{\mathrm{e}}\right)$ and experimentally-determined $\left(r_{0}\right)$ results for the $r(\mathrm{Au}-\mathrm{I})$ parameter arises because core-valence correlation is excluded from the present calculation and only a low-level treatment of relativity is used. Allowing for an $r(*-\mathrm{Au})$ bond which extends slightly in the $r_{0}$ geometry relative to the $r_{\mathrm{e}}$ value, the $\operatorname{CCSD}(\mathrm{T})\left(\mathrm{F} 12^{*}\right) \mathrm{AVTZ}$ calculated $\left(r_{\mathrm{e}}\right)$ and experimentally-determined $\left(r_{0}\right)$ results given in Table 3 are in very good agreement. The implication of both experimental $\left(r_{0}\right)$ and $\operatorname{CCSD}(\mathrm{T})(\mathrm{F} 12 *) \mathrm{AVTZ}\left(r_{\mathrm{e}}\right)$ results is that the $\mathrm{C} \equiv \mathrm{C}$ bond of $\mathrm{C}_{2} \mathrm{H}_{2}$ extends by $0.03 \AA$ on attachment to AuI. The angular geometry of ethyne is distorted by $\sim 14^{\circ}$ relative to the linear geometry of the free molecule. There is an associated lengthening of the $\mathrm{Au}-\mathrm{I}$ bond relative to its length in the isolated diatomic ${ }^{41}$ of $0.034(7) \AA$. The changes in the geometries of the monomer sub-units on formation of $\mathrm{C}_{2} \mathrm{H}_{2} \cdots$ AuI will be discussed further in the Conclusions.

It is possible to estimate a force constant from rotational and centrifugal distortion constants by making the approximation that each complex is a pseudodiatomic molecule ${ }^{39}$ in which the $\mathrm{C}_{2} \mathrm{H}_{2}$ and 
AuI sub-units can each be represented as point masses (Tables 1-3). The simplest treatment neglects the internal structure of each of the sub-units while the more sophisticated model provided by Millen ${ }^{42}$ accounts for differing monomer geometries and also been applied to many $\mathrm{B} \cdots \mathrm{MX}$ complexes. Each of the described methods of calculating a force constant applies only in the quadratic approximation and assumes that the intermolecular stretching mode, $\sigma$, lies much lower in wavenumber than other modes of the same symmetry. It has previously been noted ${ }^{43}$ that the $a b$ initio-calculated frequency of the $\Sigma^{+}$ $\mathrm{CAu}$ stretch is lower than that for $\Sigma^{+} \mathrm{AuX}$ in $\mathrm{OCAuF}$ while this ordering is reversed in $\mathrm{OCAuCl}$ and OCAuBr. It was also noted that good agreement was obtained between the vibrational frequency predicted under the simple pseudodiatomic approximation and the $\Sigma^{+} \mathrm{AuX}$ stretch, rather than the $\Sigma^{+}$ $\mathrm{CAu}$ stretch, where $\mathrm{X}=\mathrm{Cl}$ and $\mathrm{Br}$ in $\mathrm{OCAuX}$. The vibrational frequencies of $\mathrm{C}_{2} \mathrm{H}_{2} \cdots \mathrm{AuI}$ calculated at the $\operatorname{CCSD}(\mathrm{T})(\mathrm{F} 12 *) / A V T Z$ level are shown in Table 4. The wavenumber of the Au-I stretch is calculated to be $206 \mathrm{~cm}^{-1}$ while that for *-Au is $343 \mathrm{~cm}^{-1}$. Evidently, the assumption that the vibrational stretching motion of lowest frequency is well-separated from others of the same symmetry is unreliable with respect to $\mathrm{C}_{2} \mathrm{H}_{2} \cdots$ AuI. No attempt is made to calculate a force constant from the measured spectroscopic constants during the present work. A counterpoise-corrected dissociation energy $\left(D_{\mathrm{e}}\right)$ of $136 \mathrm{~kJ} \mathrm{~mol}^{-1}$ is calculated ab initio with respect to dissociation into $\mathrm{C}_{2} \mathrm{H}_{2}$ and AuI sub-units. This result is similar to the $D_{\mathrm{e}}$ of $148 \mathrm{~kJ} \mathrm{~mol}^{-1}$ established ${ }^{16}$ in respect of the dissociation of $\mathrm{C}_{2} \mathrm{H}_{2} \cdots \mathrm{CuCl}$ into $\mathrm{C}_{2} \mathrm{H}_{2}$ and $\mathrm{CuCl}$. The value of $D_{0}$ for $\mathrm{C}_{2} \mathrm{H}_{2} \cdots$ AuI, obtained after subtracting the appropriate contribution to the calculated zero point energy of the complex from $D_{\mathrm{e}}$, is $126 \mathrm{~kJ} \mathrm{~mol}^{-1}$.

\section{Nuclear Quadrupole Coupling Constants}

A perspective on the strength of the interaction between $\mathrm{C}_{2} \mathrm{H}_{2}$ and AuI can be obtained from examination of the measured nuclear quadrupole coupling constants. The sign of $\chi_{a a}(\mathrm{Au})$ changes when $\mathrm{C}_{2} \mathrm{H}_{2}$ is attached to $\mathrm{AuI}$ and there is also a significant change in the magnitude of the parameter. A significant change is also observed in $\chi_{a a}(\mathrm{I})$ which can be used to calculate the ionicity ${ }^{39}$ of the $\mathrm{Au}-\mathrm{I}$ bond; 


$$
i_{c}=1+\frac{\chi_{a a}(\mathrm{I})}{e Q q_{(n, l, 0)}(\mathrm{I})}
$$

where $e Q q_{(n, l, 0)}(\mathrm{I})$ is the coupling constant that would result from a single $n p_{z}$ electron in the isolated iodine atom ${ }^{39}$ and is $2292.44 \mathrm{MHz}$.

Measured values of $\chi_{a a}$ and ionicities for AuI, OCAuI and $\mathrm{C}_{2} \mathrm{H}_{2} \cdots$ AuI are shown in Table 5. It is apparent that attachment of either $\mathrm{C}_{2} \mathrm{H}_{2}$ or $\mathrm{CO}$ to AuI causes a significant increase in the ionicity of the AuI bond. Changes in the various $\chi_{a a}$ for $\mathrm{C}_{2} \mathrm{H}_{2} \cdots$ AuI are almost as great as those accompanying the formation of OCAuI from the monomer sub-units implying a similar strength of interaction. It was previously noted $\mathrm{d}^{43,44}$ that the fractional increase in ionicity of the AuX bond on attachment of $\mathrm{CO}$ is greatest where $\mathrm{X}$ is iodine. Evidence that the interaction between $\mathrm{Au}$ and I weakens when $\mathrm{C}_{2} \mathrm{H}_{2}$ attaches to AuI is also available in the calculated and experimentally-determined geometries presented above. Comparing experimentally-determined results for the $r_{0}$ geometries, the length of the AuI bond extends

by $0.036(15) \AA$ on attachment of $\mathrm{C}_{2} \mathrm{H}_{2}$ to AuI. A similar change was observed in the earlier study of OCAuI. The fractional changes in both ionicity and the length of the AuX bond are lower on attaching $\mathrm{CO}$ to each of $\mathrm{AuF}, \mathrm{AuCl}$ and $\mathrm{AuBr}$ (Table 5).

Values for $\chi_{b b}(\mathrm{Au})-\chi_{c c}(\mathrm{Au})$ and $\chi_{b b}(\mathrm{I})-\chi_{c c}(\mathrm{I})$ are also measured for $\mathrm{C}_{2} \mathrm{H}_{2} \cdots \mathrm{AuI}$ as shown in Table 1. The calculated significant differences between $\chi_{b b}$ and $\chi_{c c}$ for each of Au and I are consistent with the proposed bonding mechanism which involves the donation of electrons from $\pi$-orbitals of ethyne into unfilled bonding orbitals of the metal atom. The geometry of this interaction is the source of the asymmetry in the nuclear quadrupole coupling tensors. In contrast, the spectrum of OCAuI was fitted while assuming a linear molecular geometry implying donation of electron density from a lone pair on the $\mathrm{C}$ atom into unfilled orbitals on $\mathrm{Au}$.

\section{CONCLUSIONS}

The first significant conclusion to arise from this work is that the molecular geometry of the isolated $\mathrm{C}_{2} \mathrm{H}_{2} \cdots \mathrm{AuI}$ complex is $C_{2 \mathrm{v}}$ (T-shaped). Evidence for this geometry is available from the measured rotational constants, nuclear quadrupole coupling constants and from $a b$ initio calculations at the 
$\mathrm{CCSD}(\mathrm{T})\left(\mathrm{F} 12^{*}\right) \mathrm{AVTZ}$ level. The $r(\mathrm{C} \equiv \mathrm{C})$ parameter of $\mathrm{C}_{2} \mathrm{H}_{2} \cdots \mathrm{AuI}$ is longer than that in isolated ethyne by $\sim 0.032(4) \AA$ while the value of $\angle\left({ }^{*}-\mathrm{C}-\mathrm{H}\right)=194.7(12)^{\circ}$ implies distortion of the linear geometry of isolated ethyne by $14.7(12)^{\circ}$ (where the comparison is between $r_{0}$ geometries). It is apparent that the ionicity and length of the Au-I bond also change significantly on the attachment of $\mathrm{C}_{2} \mathrm{H}_{2}$ to AuI, consistent with previous studies of OCAuX which identified much smaller changes in the geometries of $\mathrm{AuX}$ sub-units where complexes have $\mathrm{X}=\mathrm{F}, \mathrm{Cl}$ or $\mathrm{Br}$. The large, calculated $\left(D_{\mathrm{e}}\right)$ binding energy of $136 \mathrm{~kJ} \mathrm{~mol}^{-1}$ with respect to dissociation into $\mathrm{C}_{2} \mathrm{H}_{2}$ and $\mathrm{AuI}$ sub-units implies that the bond between the two monomers is stronger than that found in a typical van der Waals complex and involves significant $\pi$ electron donation from $\mathrm{C}_{2} \mathrm{H}_{2}$ to $\mathrm{Au}$.

The geometry of the $\mathrm{C}_{2} \mathrm{H}_{2} \cdots$ AuI complex is consistent with empirical rules originally provided by Legon and Millen ${ }^{14,15}$ which state that in the absence of a non-bonding pair on the Lewis base, B, the axis of an MX sub-unit (where MX is a Lewis acid) in a complex of the general form $\mathrm{B} \cdot \cdot \mathrm{MX}$ intersects the internuclear axis of atoms that form a $\pi$-bond and is perpendicular to the [nodal] plane of the $\pi$ orbital. The rules were originally formulated to allow prediction of the geometries of a wide variety of hydrogen- and halogen-bonded complexes but have recently been shown to predict the basic geometries of a wide variety of much more strongly-bound $\mathrm{B} \cdot \mathrm{MX}$ complexes where $\mathrm{M}$ is either copper or silver. This work is believed to provide the first evidence that the empirical rules may also serve to predict the geometries of gold-containing complexes.

\section{ACKNOWLEDGMENTS}

The authors thank the European Research Council for postdoctoral fellowships awarded to D.P.Z, S.L.S., a postgraduate studentship for J.C.M. and for project funding (CPFTMW-307000). ACL thanks the Leverhulme Trust for an Emeritus Fellowship, the University of Bristol for a Senior Research Fellowship and Newcastle University for a Faculty of SAgE Visiting Professorship. D.P.Z. thanks Newcastle University for the award of a Faculty of SAgE Research Fellowship. D.P.T. thanks the Royal Society for a University Research Fellowship. The authors thank the EPSRC UK National Service for 
Computational Chemistry Software (NSCCS) at Imperial College London for support with computational chemistry.

\section{ASSOCIATED CONTENT}

\section{Supporting Information}

Fits of all spectroscopic parameters to measured transition frequencies. This material is available free of charge via the Internet at http://pubs.acs.org.

\section{References}

1. Christensen, C. H.; Jørgensen, B.; Rass-Hansen, J.; Egeblad, K.; Madsen, R.; Klitgaard, S. K.; Hansen, S. M.; Hansen, M. R.; Andersen, H. C.; Riisager, A., Formation of Acetic Acid by Aqueous-Phase Oxidation of Ethanol with Air in the Presence of a Heterogeneous Gold Catalyst. Angew. Chem. Int. Ed. 2006, 45, 4648-4651.

2. Nielsen, I.; Taarning, E.; Egeblad, K.; Madsen, R.; Christensen, C., Direct Aerobic Oxidation of Primary Alcohols to Methyl Esters Catalyzed by a Heterogeneous Gold Catalyst. Catal. Lett. 2007, 116, 35-40.

3. Panigrahi, S.; Basu, S.; Praharaj, S.; Pande, S.; Jana, S.; Pal, A.; Ghosh, S. K.; Pal, T., Synthesis and Size-Selective Catalysis by Supported Gold Nanoparticles: Study on Heterogeneous and Homogeneous Catalytic Process. J. Phys. Chem. C 2007, 111, 4596-4605.

4. Zhang, G.; Cui, L.; Wang, Y.; Zhang, L., Homogeneous Gold-Catalyzed Oxidative Carboheterofunctionalization of Alkenes. J. Am. Chem. Soc. 2010, 132, 1474-1475.

5. Obradors, C.; Echavarren, A. M., Intriguing Mechanistic Labyrinths in Gold(i) Catalysis. Chem. Commun. 2014, 50, 16-28.

6. Hashmi, A. S. K.; Loos, A.; Littmann, A.; Braun, I.; Knight, J.; Doherty, S.; Rominger, F., Gold(I) Complexes of KITPHOS Monophosphines: Efficient Cycloisomerisation Catalysts. $A d v$. Synth. Catal. 2009, 351, 576-582.

7. Jia, J.; Haraki, K.; Kondo, J. N.; Domen, K.; Tamaru, K., Selective Hydrogenation of Acetylene Over $\mathrm{Au} / \mathrm{Al}_{2} \mathrm{O}_{3}$ Catalyst. J. Phys. Chem. B 2000, 104, 11153-11156.

8. Chatt, J.; Duncanson, L. A., 586. Olefin Co-ordination Compounds. Part III. Infra-red Spectra and Structure: Attempted Preparation of Acetylene Complexes. J. Chem. Soc. (Res.) 1953, 29392947.

9. Pyykkö, P., Theoretical Chemistry of Gold. Angew. Chem. Int. Ed. 2004, 43, 4412-4456.

10. Stringer, K. L.; Citir, M.; Metz, R. B., Photofragment Spectroscopy of $\pi$ Complexes: $\mathrm{Au}^{+}\left(\mathrm{C}_{2} \mathrm{H}_{4}\right)$ and $\mathrm{Pt}^{+}\left(\mathrm{C}_{2} \mathrm{H}_{4}\right)$. J. Phys. Chem. A. 2004, 108, 6996-7002.

11. Halbert, S.; Gerard, H., A Computational Study of the Effects of Ancillary Ligands on Copper(i)Ethylene Interaction. New J. Chem. 2015, 39, 5410-5419.

12. Sanchez-Sanz, G.; Alkorta, I.; Elguero, J.; Yanez, M.; Mo, O., Strong Interactions Between Copper Halides and Unsaturated Systems: New Metallocycles? Or the Importance of Deformation. Phys. Chem. Chem. Phys 2012, 14, 11468-11477.

13. Zhang, G.; Yue, H.; Weinhold, F.; Wang, H.; Li, H.; Chen, D., Resonance Character of Copper/Silver/Gold Bonding in Small Molecule $\cdots \mathrm{M}-\mathrm{X}\left(\mathrm{X}=\mathrm{F}, \mathrm{Cl}, \mathrm{Br}, \mathrm{CH}_{3}, \mathrm{CF}_{3}\right)$ Complexes. Chem. Phys. Chem. 2015, 16, 2424-2431.

14. Legon, A. C.; Millen, D. J., Angular Geometries and Other Properties of Hydrogen-Bonded Dimers: a Simple Electrostatic Interpretation of the Success of the Electron-Pair Model. Chem. Soc. Rev. 1987, 16, 467-498. 
15. Legon, A. C.; Millen, D. J., Determination of Properties of Hydrogen-Bonded Dimers by Rotational Spectroscopy and a Classification of Dimer Geometries. Faraday. Discuss. 1982, 73, 71-87.

16. Stephens, S. L.; Bittner, D. M.; Mikhailov, V. A.; Mizukami, W.; Tew, D. P.; Walker, N. R.; Legon, A. C., Changes in the Geometries of $\mathrm{C}_{2} \mathrm{H}_{2}$ and $\mathrm{C}_{2} \mathrm{H}_{4}$ on Coordination to $\mathrm{CuCl}$ Revealed by Broadband Rotational Spectroscopy and Ab-Initio Calculations. Inorg. Chem. 2014, 53, 10722-10730.

17. Stephens, S. L.; Tew, D. P.; Mikhailov, V. A.; Walker, N. R.; Legon, A. C., A Prototype Transition-Metal Olefin Complex $\mathrm{C}_{2} \mathrm{H}_{4} \cdots \mathrm{AgCl}$ Synthesised by Laser Ablation and Characterised by Rotational Spectroscopy and Ab Initio Methods. J. Chem. Phys. 2011, 135, 024315.

18. Zaleski, D. P.; Stephens, S. L.; Tew, D. P.; Bittner, D. M.; Walker, N. R.; Legon, A. C., Distortions of Ethyne When Complexed with a Cuprous or Argentous Halide: the Rotational Spectrum of $\mathrm{C}_{2} \mathrm{H}_{2} \cdots$ CuF. Phys. Chem. Chem. Phys. 2015, 17, 19230-19237.

19. Stephens, S. L.; Mizukami, W.; Tew, D. P.; Walker, N. R.; Legon, A. C., Distortion of Ethyne on Formation of a $\pi$ Complex with Silver Chloride: $\mathrm{C}_{2} \mathrm{H}_{2} \cdots \mathrm{Ag}-\mathrm{Cl}$ Characterised by Rotational Spectroscopy and Ab Initio Calculations. J. Chem. Phys. 2012, 137, 174302.

20. Stephens, S. L.; Zaleski, D. P.; Mizukami, W.; Tew, D. P.; Walker, N. R.; Legon, A. C., Distortion of Ethyne on Coordination to Silver Acetylide, $\mathrm{C}_{2} \mathrm{H}_{2} \cdots \mathrm{AgCCH}$, Characterised by Broadband Rotational Spectroscopy and Ab Initio Calculations. J. Chem. Phys. 2014, 140, 124310.

21. Kukolich, S. G.; Drouin, B. J.; Indris, O.; Dannemiller, J. J.; Zoller, J. P.; Herrmann, W. A., Microwave Spectra, Density Functional Theory Calculations and Molecular Structure of Acetylenemethyldioxorhenium. J. Chem. Phys. 2000, 113, 7891-7900.

22. Zaleski, D. P.; Stephens, S. L.; Walker, N. R., A Perspective on Chemistry in Transient Plasma from Broadband Rotational Spectroscopy. Phys. Chem. Chem. Phys. 2014, 16, 25221-25228.

23. Stephens, S. L.; Mizukami, W.; Tew, D. P.; Walker, N. R.; Legon, A. C., Molecular Geometry of OC...AgI Determined by Broadband Rotational Spectroscopy and Ab Initio Calculations. $J$. Chem. Phys. 2012, 136, 064306.

24. Brown, G. G.; Dian, B. C.; Douglass, K. O.; Geyer, S. M.; Shipman, S. T.; Pate, B. H., A Broadband Fourier Transform Microwave Spectrometer Based on Chirped Pulse Excitation. Rev. Sci. Instrum. 2008, 79, 053103.

25. Stephens, S. L.; Walker, N. R., Determination of Nuclear Spin-Rotation Coupling Constants in $\mathrm{CF}_{3} \mathrm{I}$ by Chirped-Pulse Fourier-Transform Microwave Spectroscopy. J. Mol. Spectrosc. 2010, 263, 27-33.

26. Legon, A. C., Isolation and Characterisation of some Transient Complexes of Chemical Interest Using Pulsed-Nozzle, Fourier-Transform Microwave Spectroscopy. J. Mol. Struct. 1992, 266, 21-37.

27. Batten, R. C.; Cole, G. C.; Legon, A. C., Rotational Spectroscopy of a Weak Complex of Thiirane and Ethyne: the Identification and Properties of a Highly Nonlinear S $\cdots \mathrm{H}-\mathrm{C}$ Hydrogen Bond. $J$. Chem. Phys. 2003, 119, 7903-7912.

28. Batten, S. G.; Legon, A. C., OC-Cu-I Synthesized by Reaction of Laser-Ablated Cu with a $\mathrm{CH}_{3} \mathrm{I} / \mathrm{CO} / \mathrm{Ar}$ Mixture and Characterised by Pulsed-Jet, Fourier-Transform Microwave Spectroscopy. Chem. Phys. Lett. 2006, 422, 192-197.

29. Raghavachari, K.; Trucks, G. W.; Pople, J. A.; Head-Gordon, M., A Fifth-Order Perturbation Comparison of Electron Correlation Theories. Chem. Phys. Lett. 1989, 157, 479-483.

30. Hattig, C.; Tew, D. P.; Kohn, A., Communications: Accurate and Efficient Approximations to Explicitly Correlated Coupled-Cluster Singles and Doubles, CCSD-F12. J. Chem. Phys. 2010, 132, 231102.

31. Hattig, C.; Klopper, W.; Kohn, A.; Tew, D. P., Explicitly Correlated Electrons in Molecules. Chem. Rev. 2012, 112, 4-74.

32. Kendall, R. A.; Dunning, T. H.; Harrison, R. J., Electron Affinities of the First-Row Atoms Revisited. Systematic Basis Sets and Wave Functions. J. Chem. Phys. 1992, 96, 6796.

33. Peterson, K. A.; Puzzarini, C., Systematically Convergent Basis Sets for Transition Metals. II. Pseudopotential-Based Correlation Consistent Basis Sets for the Group $11(\mathrm{Cu}, \mathrm{Ag}, \mathrm{Au})$ and 12 (Zn, Cd, Hg) Elements. Theor. Chem. Acc. 2005, 114, 283-296. 
34. Peterson, K.A.; Shepler, B.C.; Figgen, D.; Stoll, H., On the Spectroscopic and Thermochemical Properties of ClO, BrO, IO, and Their Anions, J. Phys. Chem. A 2006, 110, 13877-13883.

35. Figgen, D.; Rauhut, G.; Dolg, M.; Stoll, H., Energy-Consistent Pseudopotentials for Group 11 and 12 Atoms: Adjustment to Multi-configuration Dirac-Hartree-Fock Data, Chem. Phys. 2005, $311,227-244$.

36. Werner, H.-J.; Knowles, P. J.; Knizia, G.; Manby, F. R.; Schütz, M. MOLPRO, A General Purpose Quantum Chemistry Program Package. WIREs Comput. Mol. Sci. 2012, 2, 242-253. DOI 10.1002/wcms.82. See also: http://www.molpro.net).

37. PGOPHER, a Program for Simulating Rotational, Vibrational and Electronic Structure, C. M. Western, University of Bristol, http://pgopher.chm.bris.ac.uk

38. Kisiel, Z., Least-Squares Mass-Dependence Molecular Structures for Selected Weakly Bound Intermolecular Clusters. J. Mol. Spectrosc. 2003, 218, 58-67.

39. Gordy, W.; Cook, R. L., Microwave Molecular Spectra, $2^{\text {nd }}$ ed.; Wiley Interscience: New York, 1984.

40. Herman, M.; Campargue, A.; El Idrissi, M. I.; Vander Auwera, J., Vibrational Spectroscopic Database on Acetylene, $\tilde{\mathrm{X}}^{1} \Sigma_{\mathrm{g}}{ }^{+}\left({ }^{12} \mathrm{C}_{2} \mathrm{H}_{2},{ }^{12} \mathrm{C}_{2} \mathrm{D}_{2}\right.$, and $\left.{ }^{13} \mathrm{C}_{2} \mathrm{H}_{2}\right)$. J. Phys. Chem. Ref. Data 2003, 32, 921-1361.

41. Reynard, L. M.; Evans, C. J.; Gerry, M. C. L., The Pure Rotational Spectrum of AuI. J. Mol. Spectrosc. 2001, 205, 344-346.

42. Millen, D. J., Determination of Stretching Force-Constants of Weakly Bound Dimers from Centrifugal-Distortion Constants. Can. J. Chem. 1985, 63, 1477-1479.

43. Evans, C. J.; Reynard, L. M.; Gerry, M. C. L., Pure Rotational Spectra, Structures, and Hyperfine Constants of OC-AuX (X = F, Cl, Br). Inorg. Chem. 2001, 40, 6123-6131.

44. Walker, N. R.; Francis, S. G.; Matthews, S. L.; Rowlands, J. J.; Legon, A. C., Microwave Spectrum and Structure of Carbonyl Gold Iodide, OCAuI. Mol. Phys. 2007, 105, 861-869.

\section{For Table of Contents Only}

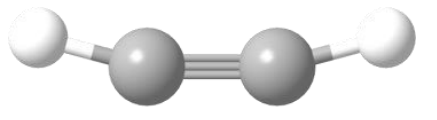

A complex of $\mathrm{C}_{2} \mathrm{H}_{2}$ and $\mathrm{AuI}$ has been generated through laser ablation of gold in the presence of a gaseous sample containing small amounts of $\mathrm{C}_{2} \mathrm{H}_{2}$ and $\mathrm{CF}_{3} \mathrm{I}$. Broadband rotational spectroscopy reveals that the complex has $C_{2 \mathrm{v}}$ symmetry and that the geometry of free $\mathrm{C}_{2} \mathrm{H}_{2}$ changes on attachment to

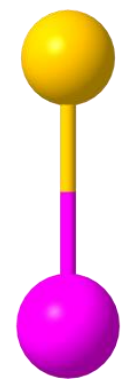
AuI. Comparing $r_{0}$ geometries, the $\mathrm{C} \equiv \mathrm{C}$ bond extends by $0.032(4) \AA$ while the $\mathrm{H}$ atoms move away from $\mathrm{Au}$ such that $\angle(\mathrm{CCH})$ expands from $180^{\circ}$ to 194.7(12) $)^{\circ}$ 
Table 1. Spectroscopic constants determined for three isotopologues of $\mathrm{C}_{2} \mathrm{H}_{2} \cdots$ AuI.

\begin{tabular}{|c|c|c|c|}
\hline $\begin{array}{l}\text { Spectroscopic } \\
\text { constant }\end{array}$ & $\begin{array}{c}{ }^{12} \mathrm{C}_{2} \mathrm{H}_{2} \\
\vdots \\
\mathrm{AuI}\end{array}$ & $\begin{array}{c}{ }^{12} \mathrm{C}_{2} \mathrm{D}_{2} \\
\vdots \\
\mathrm{AuI}\end{array}$ & $\begin{array}{c}{ }^{13} \mathrm{C}_{2} \mathrm{D}_{2} \\
\vdots \\
\mathrm{AuI}\end{array}$ \\
\hline$A_{0} / \mathrm{MHz}$ & $34399(36)^{\mathrm{a}}$ & $25179(13)$ & $24213(13)$ \\
\hline$B_{0} / \mathrm{MHz}$ & $711.28170(6)$ & $692.747417(73)$ & $678.257387(92)$ \\
\hline$C_{0} / \mathrm{MHz}$ & $696.65502(6)$ & $673.887794(76)$ & $659.504581(85)$ \\
\hline$\Delta_{J K} / \mathrm{kHz}$ & $4.001(16)$ & $3.461(24)$ & $3.403(26)$ \\
\hline$\left[\Delta_{J} \times 10^{2}\right] / \mathrm{kHz}$ & $3.172(21)$ & $3.026(25)$ & $2.618(31)$ \\
\hline$\chi_{a a}(\mathrm{Au}) / \mathrm{MHz}$ & $-808.678(53)$ & $-809.865(79)$ & $-810.30(11)$ \\
\hline$\left[\chi_{b b}(\mathrm{Au})-\chi_{c c}(\mathrm{Au})\right] / \mathrm{MHz}$ & $358.20(11)$ & $360.35(29)$ & $360.72(35)$ \\
\hline$\chi_{a a}(\mathrm{I}) / \mathrm{MHz}$ & $-1013.001(43)$ & $-1012.442(82)$ & $-1012.29(12)$ \\
\hline$\left[\chi_{b b}(\mathrm{I})-\chi_{c c}(\mathrm{I})\right] / \mathrm{MHz}$ & -219.67 & $-219.87(27)$ & $-218.94(33)$ \\
\hline$N^{b}$ & 532 & 443 & 364 \\
\hline$\sigma_{\text {r.m.s. }} / \mathrm{kHz}^{\mathrm{c}}$ & 6.7 & 7.3 & 8.0 \\
\hline$\Delta_{0} /\left(\mathrm{u} \AA^{2}\right)^{\mathrm{d}}$ & $0.23(2)$ & $0.35(1)$ & $0.31(1)$ \\
\hline$P_{a} /\left(\mathrm{u} \AA^{2}\right)$ & $710.6(7)$ & $745.3(4)$ & $729.7(4)$ \\
\hline$P_{b} /\left(\mathrm{u} \AA^{2}\right)$ & $14.80(2)$ & $20.24(1)$ & 21.03(1) \\
\hline$P_{c} /\left(\mathrm{u} \AA^{2}\right)$ & $-0.113(1)$ & $-0.174(1)$ & $-0.157(1)$ \\
\hline
\end{tabular}

${ }^{a}$ Numbers in parentheses are one standard deviation in units of the last significant figure.

${ }^{\mathrm{b}}$ Number of hyperfine components included in the fit.

${ }^{\mathrm{c}}$ rms deviation of the fit.

${ }^{\mathrm{d}}$ Inertia defect as defined in equation 2. 
Table 2. Geometry of $\mathrm{C}_{2} \mathrm{H}_{2} \cdots$ AuI.

\begin{tabular}{llll}
\hline \hline & & \multicolumn{2}{c}{$\mathrm{C}_{2} \mathrm{H}_{2} \cdots \mathrm{AuI}$} \\
& $r_{0}$ & $r_{s}$ & $\begin{array}{l}r_{\mathrm{e}} \\
\end{array}$ \\
& (exp.) & $($ exp. $)$ & $(\mathrm{CCSD}(\mathrm{T})(\mathrm{F} 12 *)(\mathrm{AVTZ})$ \\
\hline$r(*-\mathrm{Au}) / \AA$ & $2.057(15)$ & - & 2.077 \\
$r(\mathrm{Au}-\mathrm{I}) / \AA$ & $2.507(4)$ & - & 2.522 \\
$r(\mathrm{C} \equiv \mathrm{C}) / \AA$ & $1.239(4)$ & $1.264(4)$ & 1.234 \\
$r(\mathrm{C}-\mathrm{H}) / \AA$ & {$[1.0692]^{\mathrm{b}}$} & $1.038(2)$ & 1.068 \\
$\angle(*-\mathrm{C}-\mathrm{H}) / \circ$ & $194.7(12)$ & $195.1(7)$ & 193.9 \\
& & & \\
$a_{\mathrm{Au}} / \AA$ & $-0.737(3)$ & - & -0.741 \\
$a_{\mathrm{I}} / \AA$ & $1.752(2)$ & - & 1.780 \\
$a^{*}=a_{\mathrm{C}} / \AA$ & $-2.793(12)$ & $-2.795(1)$ & -2.818 \\
$b_{\mathrm{C}} / \AA$ & $\pm 0.619(2)$ & $\pm 0.632(2)$ & \pm 0.617 \\
$a_{\mathrm{H}} / \AA$ & $-3.065(12)$ & $-3.065(2)$ & -3.074 \\
$b_{\mathrm{H}} / \AA$ & $\pm 1.653(4)$ & $\pm 1.635(1)$ & \pm 1.655 \\
\hline \hline
\end{tabular}

${ }^{a}$ Numbers in parentheses are one standard deviation in units of the last significant figure.

${ }^{\mathrm{b}}$ Fixed to the value obtained by correcting the $r_{\mathrm{e}}$ result calculated at the CCSD(T)(F12*)/AVTZ level for the difference between the experimentally-measured $r_{0}$ and $r_{\mathrm{e}}$ distances of $\mathrm{C}_{2} \mathrm{H}_{2}$. 
Table 3. Geometries of isolated $\mathrm{C}_{2} \mathrm{H}_{2}$ and AuI.

\begin{tabular}{llll}
\hline \hline & \multicolumn{3}{c}{ AuI } \\
\hline & $r_{0}$ & $r_{\mathrm{e}}$ & $r_{\mathrm{e}}$ \\
& $(\text { exp. })^{\mathrm{a}}$ & $(\text { exp. })^{\mathrm{a}}$ & $\left(\mathrm{CCSD}(\mathrm{T})\left(\mathrm{F} 12^{*}\right)(\mathrm{AVTZ})\right.$ \\
\hline$r(\mathrm{Au}-\mathrm{I}) / \AA$ & 2.4728 & 2.4711 & 2.4896 \\
& & & $2.4881[\mathrm{fc}-\mathrm{CCSD}(\mathrm{T}) / \mathrm{CV} 5 Z]$ \\
& & & $2.4758[+\mathrm{CV} / \mathrm{CV} 5 \mathrm{Z}]$ \\
& & & $2.4792[+\mathrm{T}]$ \\
& & $\mathrm{C}_{2} \mathrm{H}_{2}$ & \\
\hline & & $r_{\mathrm{e}}$ & $r_{\mathrm{e}}$ \\
& $r_{0}$ & $(\text { exp. })^{\mathrm{b}}$ & $\left(\mathrm{CCSD}(\mathrm{T})\left(\mathrm{F} 12^{*}\right) \mathrm{AVTZ}\right)$ \\
\hline$r(\mathrm{C} \equiv \mathrm{C}) / \AA$ & $(\mathrm{exp} .)^{\mathrm{b}}$ & $1.20286(3)$ & 1.2055 \\
$r(\mathrm{C}-\mathrm{H}) / \AA$ & $1.06553(6)$ & $1.06166(6)$ & 1.0631 \\
\hline & $1.06238(2)$ & ${ }^{12} \mathrm{C}_{2} \mathrm{H}_{2} \mathrm{D}_{2}$ & ${ }^{13} \mathrm{C}_{2} \mathrm{D}_{2}$ \\
\hline$B_{0} / \mathrm{MHz}$ & $35274.9693(54)^{\mathrm{b}}$ & $25418.629^{\mathrm{b}}$ & $24484.418^{\mathrm{c}}$ \\
\hline \hline
\end{tabular}

${ }^{\text {a }}$ Reference 41

${ }^{\mathrm{b}}$ Reference 19

${ }^{\mathrm{c}}$ Calculated using data from reference 40 
Table 4. Calculated vibrational wavenumbers of $\mathrm{C}_{2} \mathrm{H}_{2} \cdots$ AuI.

\begin{tabular}{|c|c|c|c|c|}
\hline & Sym. & $\begin{array}{c}\mathrm{C}_{2} \mathrm{H}_{2} \cdots \text { AuI } \\
\text { Wavenumber } / \mathrm{cm}^{-1}\end{array}$ & Sym. & $\begin{array}{l}\mathrm{C}_{2} \mathrm{H}_{2}+\mathrm{AuI} \\
\text { Wavenumber } / \mathrm{cm}^{-1}\end{array}$ \\
\hline *-Au-I bend & $\mathrm{B}_{1}$ & 89 & - & - \\
\hline *-Au-I bend & $\mathrm{B}_{2}$ & 167 & - & - \\
\hline $\mathrm{Au}-\mathrm{I}$ stretch & $\mathrm{A}_{1}$ & 206 & $\Sigma^{+}$ & 212 \\
\hline *-Au stretch & $\mathrm{A}_{1}$ & 343 & - & - \\
\hline $\mathrm{Au}-\mathrm{HCCH}$ rock & $\mathrm{B}_{2}$ & 380 & - & - \\
\hline HCCH wag & $\mathrm{B}_{2}$ & 742 & $\Pi_{\mathrm{g}}$ & 617 \\
\hline HCCH wag & $\mathrm{A}_{2}$ & 14223 & $\Pi_{\mathrm{g}}^{\circ}$ & 617 \\
\hline $\mathrm{HCCH}$ bend & $\mathrm{B}_{1}$ & 733 & $\Pi_{\mathrm{u}}$ & 751 \\
\hline $\mathrm{HCCH}$ bend & $\mathrm{A}_{1}$ & 783 & $\Pi_{\mathrm{u}}$ & 751 \\
\hline $\mathrm{C}-\mathrm{C}$ stretch & $\mathrm{A}_{1}$ & 1853 & $\Sigma_{\mathrm{g}}^{+}$ & 2011 \\
\hline $\mathrm{C}-\mathrm{H}$ stretch & $\mathrm{B}_{2}$ & 3349 & $\Sigma_{\mathrm{u}}^{-}$ & 3411 \\
\hline $\mathrm{C}-\mathrm{H}$ stretch & $\mathrm{A}_{1}$ & 3435 & $\sum_{\mathrm{g}}^{+}$ & 3505 \\
\hline
\end{tabular}


Table 5. Nuclear quadrupole coupling constants and ionicities of $\mathrm{C}_{2} \mathrm{H}_{2} \cdots A u X$.

\begin{tabular}{lllll}
\hline \hline & $\chi_{a a}(\mathrm{Au}) / \mathrm{MHz}$ & $\chi_{a a}(\mathrm{X}) / \mathrm{MHz}$ & $\mathrm{i}_{\mathrm{c}}$ & $\Delta r^{\mathrm{a}} / \AA$ \\
\hline $\mathrm{AuI}^{\mathrm{b}}$ & 78.27 & -1707.9 & 0.26 & - \\
$\mathrm{C}_{2} \mathrm{H}_{2} \cdots \mathrm{AuI}$ & -808.678 & -1013.001 & 0.56 & $+0.036(15)$ \\
$\mathrm{OC} \cdots \mathrm{AuI}^{\mathrm{c}}$ & -961.3 & -981.0 & 0.58 & $+0.030^{\mathrm{d}}$ \\
\hline $\mathrm{AuBr}$ & 37.3 & 492.3 & 0.38 & - \\
$\mathrm{OC} \cdots \mathrm{AuBr}^{\mathrm{c}}$ & -999.1 & 285.1 & 0.64 & +0.020 \\
\hline $\mathrm{AuCl}$ & 9.6 & -62.0 & 0.44 & - \\
$\mathrm{OC} \cdots \mathrm{AuCl}^{\mathrm{c}}$ & -1026.0 & -36.4 & 0.67 & +0.018 \\
\hline $\mathrm{AuF}$ & -53.3 & - & - & - \\
$\mathrm{OC} \cdots \mathrm{AuF}^{\mathrm{c}}$ & -1006.3 & - & - & -0.009 \\
\hline \hline
\end{tabular}

${ }^{\text {a }}$ Extension in $\mathrm{Au}-\mathrm{I}$ bond relative to the same distance in the isolated AuI molecule ( $r_{0}$ geometry).

${ }^{\mathrm{b}}$ Reference 41

${ }^{c}$ References 43 and 44

${ }^{\mathrm{d}}$ Determined through calculation rather than fitting so no standard deviation is assigned to this value. 